\title{
RELAÇÕES INTELECTUAIS ASSIMÉTRICAS: A "POLÊMICA" HISTÓRICA ENTRE ALFREDO PIMENTA E GUSTAVO BARROSO
}

\author{
INTELLECTUAL ASYMMETRIC RELATIONS: A "POLEMIC" \\ HISTORY BETWEEN ALFREDO PIMENTA AND GUSTAVO \\ BARROSO
}

DOI: http://dx.doi.org/10.15448/2178-3748.2016.1.22777

\author{
Luiz Mário Ferreira Costa \\ Doutor em História \\ luizmariofc@gmail.com
}

\begin{abstract}
RESUMO: O objetivo deste artigo é demonstrar a assimetria de sentimentos que se escondia por trás de uma suposta fraternidade intelectual estabelecida entre Brasil e Portugal, nas primeiras décadas do século XX. Para isso, escolhemos dois importantes autores luso-brasileiros: Alfredo Pimenta e Gustavo Barroso. Ainda que ambos defendessem interpretações históricas semelhantes, cujo mote central era a valorização do antigo Império colonial português e, consequentemente, seu legado civilizatório deixado para o mundo, eles acabariam ilustrando uma curiosa "disputa" em torno da verdade histórica. Esse breve contato entre Brasil-Portugal foi aqui analisado com base nas críticas de Alfredo Pimenta ao livro A Senhora de Pangim (1940), de Gustavo Barroso. A partir daí, vimos emergir não somente as vaidades e os desejos desses homens em se fazer superiores, mas, fundamentalmente, um complexo comportamento heroico, que caracterizou o imaginário social da época. Tal heroísmo foi incorporado tanto nas obras de Alfredo Pimenta quanto nas de Gustavo Barroso e marcaria de forma definitiva algumas construções politico-ideológicas autoritárias em seus respectivos países.
\end{abstract}

PALAVRAS-CHAVE: Intelectuais luso-brasileiros; historiografia; comportamento heroico.

ABSTRACT: The purpose of this article is to demonstrate the asymmetry of feelings that lurked behind a supposed intellectual brotherhood established between Brazil and Portugal, in the first decades of the twentieth century, so we chose two important Luso-Brazilian authors, Alfredo Pimenta and Gustavo Barroso. Although both defend like historical interpretations, whose main objective was the appreciation of the former Portuguese colonial empire and, consequently, its civilizational legacy to the world, they would end up illustrating a curious "dispute" around the historical truth. This brief contact between Brazil and Portugal was analyzed here based on the criticism of Alfredo pepper the book A Senhora de Pangim (1940) of Gustavo Barroso. From there we saw emerge not only the vanities and desires of these men, in making superiors, but fundamentally a complex heroic behavior that characterized the social imaginary of the time. Such heroism was incorporated both in the works of Alfredo Pimenta as in Gustavo Barroso, and mark definitively some politico-ideological constructions authoritarian in their respective countries.

KEYWORDS: Luso-Brazilian intellectuals; historiography; heroic behavior.

\section{CONSIDERAÇÕES INICIAIS}

O temperamento polêmico e, muitas vezes, extravagante dos intelectuais sempre despertou grande interesse dos meios de comunicação, do grande público e, principalmente, 
dos historiadores das ideias (ABREU, 1996). Como não lembrarmos, por exemplo, da ampla exposição da obra e da vida pessoal de Jean-Paul Sartre (JACOBELIS, 2005), da postura crítica de Howard Zinn (2005) contra a política militar norte-americana, ou mesmo, da discutível "teoria da complexidade" de Edgar Morin (2015). O fato é que, em meio às crises políticas, econômicas e, principalmente, diante de uma crise moral, os intelectuais, frequentemente, são "chamados" a colaborar publicamente com suas interpretações da realidade, seus ideais políticos e suas visões de mundo. Sobre esses homens, vistos como os "modernos magos" da comunicação, recairiam a responsabilidade e a prerrogativa de restabelecer o valor da inteligência que havia se perdido no caos da sociedade.

A “convocação" do intelectual teria ocorrido pela primeira vez na França, em fins do século XIX, num episódio que ficou conhecido como o "caso Dreyfus". Com base nos desdobramentos dessa polêmica, Michel Winock (2000) sugeriu que os intelectuais ganharam um importante status social e, além disso, contribuíram para fortalecer as liberdades republicanas, o desenvolvimento do ensino público e a imprensa contemporânea (WINOCK, 2000, p.791). Desde então, esta profunda renovação na forma de perceber o poder do intelectual se espraiou por toda a sociedade Ocidental e, naturalmente, tanto Portugal quanto Brasil produziram as mais variadas e antagônicas formas de leitura desse poder, seja por autores ditos de "esquerda", seja por autores considerados de "direita". Deste modo, escolhemos analisar a manifestação do poder intelectual a partir do breve, porém significativo contato ocorrido entre dois dos mais destacados autores reacionários, das primeiras décadas do século XX, o português Alfredo Pimenta e o brasileiro Gustavo Barroso. Ambos armados com suas "penas afiadas" acreditavam romper com a inércia e com o silêncio dos "pensadores" de seu tempo e se autodeclaravam os "heróis" da renovação da "Inteligência" luso-brasileira.

\section{EMBATES E POLÊMICAS ENTRE INTELECTUAIS LUSO-BRASILEIROS}

O primeiro encontro entre Alfredo Pimenta e Gustavo Barroso, de que se tem registro, provavelmente ocorreu nos salões da "Academia Portuguesa de História", depois que esta foi reinaugurada no dia 19 de maio de 1936 por Salazar (COSTA, 2015, p.97). A instituição era considerada a herdeira e a continuadora oficial da "Academia Real da História Portuguesa", fundada por D. João V, em 8 de Dezembro de 1720, que ressurgiu atrelada ao Arquivo Nacional da Torre do Tombo e sob a responsabilidade do Ministério da Educação Nacional. Foi estruturada na forma de uma "agremiação especializada dos eruditos", que se 
dedicavam à investigação e à reconstrução crítica do passado. Seu objetivo principal era o de estimular e coordenar os esforços revisionistas para a "reintegração" daquilo que seus membros entendiam como a "verdade nos estudos históricos", além de trabalhar no sentido de enriquecer e qualificar a documentação histórica de Portugal. Dois anos após a reabertura da Academia, em sessão oficial do dia 1 de janeiro de 1938, o nome de Alfredo Pimenta aparecia pela primeira vez nas atas das reuniões. Nesta mesma ocasião, o intelectual Gustavo Barroso, juntamente com Afonso Taunay, Afrânio Peixoto, Artur Guimarães de Araújo Jorge, Conde de Afonso Celso, Francisco José de Oliveira Viana, Max Fleiuss, Pedro Calmon, Rodolfo Garcia, era nomeado acadêmico da ilustre instituição. (BOLETIM, 1937-1938).

Gustavo Barroso, sempre que viajava a Portugal, fazia questão de marcar presença nas reuniões da APH. Em 1940, por exemplo, em Sessão Ordinária do dia 26 de junho, o intelectual, ao lado de Edmundo da Luz Pinto, foi um dos representantes da Embaixada que o governo brasileiro enviou para as "Comemorações Centenárias e a Exposição do Mundo Português". O evento tinha como propósito comemorar a data da Fundação do Estado Português (1140) e da Restauração da Independência (1640). Por trás destes festejos, estava a vontade de Salazar em celebrar o Estado Novo e de passar para o restante do mundo a imagem de que o país foi o protagonista de algumas das páginas mais importantes da história universal. Com este intuito, foram realizados grandes cortejos durante os quais se narrava uma história de conquistas e de missão civilizatória. Além disso, aconteceram também encontros entre acadêmicos de vários outros países. Numa dessas ocasiões, Gustavo Barroso recebeu elogios e agradecimentos pelas "palavras de amizade", com as quais descreveu a ação dos portugueses no mundo e, especialmente, no Brasil (BOLETIM, 1937-1938, p.93).

No dia 13 de novembro do mesmo ano, Gustavo Barroso mais uma vez assinava a ata da APH, na qual falou "em brilhantes rasgos oratórios" sobre a intervenção dos jesuítas portugueses. O discurso do acadêmico novamente exaltava os feitos de Portugal no Brasil e destacava a necessidade de fortalecer os laços de fraternidade entre as nações. Sua fala, floreada de elogios e apologias, parecia criar um mundo simbólico em que os lusitanos e os brasileiros estariam conectados para sempre. A admiração pelos colonizadores só fazia por fortalecer o sentimento nacionalista de Gustavo Barroso, pois vangloriar os bravos descobridores significava fomentar uma estirpe nobre para o Brasil. Como era de se esperar, suas palavras despertavam uma reação muito positiva em todos aqueles intelectuais presentes na $\mathrm{APH}$, pois fazia coro ao discurso de que Portugal era um império fundador de grandes pátrias e, o Brasil, por sua vez, seria a comprovação desta ideia. Como forma de agradecimento ao governo brasileiro pelo envio da Embaixada, na ocasião das 
"Comemorações", o escritor Júlio Dantas iria ao Brasil entregar o "colar" da APH aos nove acadêmicos, dentre eles, o diretor do Museu Histórico Nacional, Gustavo Barroso (BOLETIM, 1937-1938, p.91).

É importante salientar que as Comemorações Centenárias de 1940 não foram marcadas somente pela celebração dos laços de fraternidade entre Portugal e Brasil, pois aconteceram tensões importantes, principalmente durante o "Congresso Luso Brasileiro de História”, que era parte das comemorações. Celine Blotta (2009) argumentou que do ponto de vista historiográfico, o "Congresso" estabeleceu como objetivo esclarecer fatos cujas análises históricas se mostravam divergentes em Portugal e no Brasil, uma vez que não se pretendia estabelecer ali uma "unidade perfeita" entre os historiadores de ambos os países. Deste modo, em alguns momentos, os descontentamentos dos portugueses foram deflagrados, sobretudo quando os temas tratados pelos brasileiros eram incômodos, como, por exemplo, os movimentos de independência. (BLOTTA, 2009, p.114).

Porém, o que verdadeiramente nos interessa aqui é retomar a linha discursiva de Gustavo Barroso, onde a imagem gloriosa de Portugal se transformava na figura de mãe espiritual da coesão brasileira. Em seu raciocínio, foram as tradições lusitanas, dentre elas a própria língua e todo o universo simbólico daí decorrente, que explicariam porque o Brasil, ao contrário das colônias hispano-americanas, conseguiu preservar a sua integridade territorial. Sendo assim, não causaria estranheza que diante de todas as defesas apaixonadas realizadas por Gustavo Barroso a Portugal, o brasileiro conseguisse estabelecer um contato bastante fraterno com importantes setores da intelectualidade lusitana. Este bom relacionamento lhe rendeu algumas publicações, entre elas, A Senhora de Pangim (1940), publicada pela prestigiada "Agência Geral das Colónias", órgão oficial do governo português.

A obra estava inserida no panorama dos debates em torno do "Mundo Português" nos séculos XVII e XVIII e fazia parte das "Comemorações Centenárias". A personagem principal era um "símbolo" desse mundo cosmopolita, que incluía Brasil, Portugal, África, Índia e o extremo oriente. Igualmente, desde o início, o autor afirmava que o episódio em que o romance estava fundamentado era "autenticamente histórico" e, por mais que fosse extraordinária a aventura de D. Maria Ursula de Abreu Lencastre, a heroína teria existido de verdade.

Todavia, o episodio em que se fundamenta êste romance é autenticamente histórico. Nas "Efemérides Nacionais", de Teixeira de Melo, lê-se o

Oficina do Historiador, Porto Alegre, EDIPUCRS v. 9, n. 1, jan./jun. 2016, 
seguinte, sob a data de 1 de Setembro de 1700: “Assenta praça de soldado em Lisboa, sob o nome de Baltasar do Couto Cardoso, a fluminense D. Maria Ursula de Abreu Lencastre, filha de João de Abreu Oliveira, na idade de dezoito anos. Fugira para isso da casa paterna. E, como soldado partiu essa nossa heroína para a Índia. Ali tomou parte em muitos combates, fez prodígios de valor e procedeu sempre de um modo irrepreensível. (BARROSO, 1940, p.7).

A impressionante história de uma brasileira que se passou por homem, soldado "Cardoso", enganando as autoridades para lutar nos mais distantes domínios portugueses, por si só, já representava um excelente tema para qualquer escritor. Gustavo Barroso não deixou escapar essa oportunidade e acrescentou tonalidades romanescas à história. Deste modo, escrevia o autor com enorme empolgação, que o "soldado Cardoso" participou com "bravura" de grandes batalhas, destacando o "assalto à fortaleza de Amboina" como a mais importante das vitórias da heroína brasileira.

Refere-se que no assalto à fortaleza de Amboina foi ela, o soldado Cardoso, um dos primeiros e mostrar a intrepidez varonil na tomada das ilhas de Corjuém e Penelém. Depois de treze anos de serviço dessa natureza, teve baixa a 12 de Maio de 1714 e esposou o valente oficial da India, Afonso Teixeira Arrais de Melo, que fôra governador do forte de S. João Baptista, na ilha de Goa. (BARROSO, 1940, p. 7-8).

O tom hiperbólico continuava, e o intelectual descrevia a coragem com que aquela mulher, disfarçada de soldado, desempenhava os serviços do rei. Esta bravura em nome da Coroa portuguesa teria sido reconhecida pelo próprio monarca que, como recompensa, lhe concedeu a mercê do Paço de Pangim, no dia 8 de março de 1718. Com riqueza de detalhes do episódio, Gustavo Barroso acrescentava que a brasileira pagaria na "Alfandega de Goa" um xerafim por dia durante seis anos.

O Barão do Rio Branco registra desta sorte o acontecimento nas "Efemérides Brasileiras", na mesma data: "D. Maria Ursula de Abreu Lencastre, disfarçada em homem e tomando o nome de Baltasar do Couto Cardoso, assenta praça de soldado em Lisboa. Contava, então, dezoito anos de idade e era natural do Rio de Janeiro e filha de João de Abreu Oliveira. Parece que o desespero de um amor contrariado a levou fugir da casa paterna, buscando uma diversão nas aventuras da guerra. Na Índia, a heroica brasileira distinguiu-se entre os mais intrépidos soldados, principalmente na tomada da fortaleza de Amboina (1705) e na conquista das ilhas de Penelém e Corjuém (1706). Depois, comandou um dos baluartes da fortaleza de Tschaul. Obtendo baixa a 12 de maio de 1714, casou-se com um valente oficial português, Arrais de Melo, e mereceu de D. João V uma pensão e o usufruto 
do paço de Pangim. Faleceu em Goa cercada do respeito geral. (BARROSO, 1940, p.8).

Gustavo Barroso estava ciente de que poderia ser questionado quanto à veracidade da história, por isso tentou se resguardar recorrendo aos mais diversos historiadores. Em concordância com o Barão do Rio Branco, por exemplo, o autor incorporou muitos detalhes à história de D. Maria Ursula. Neste sentido, escreveu com bastante segurança que a motivação que levou a brasileira à experiência da guerra foi por conta de uma grande desilusão amorosa. Afirmava peremptoriamente que foi o "desespero de um amor contrariado" que obrigou a jovem a tomar uma medida tão drástica e perigosa. $O$ intelectual também foi buscar legitimidade na obra Brasileiras célebres (1862), de Joaquim Norberto de Souza e Silva, para tentar escapar das críticas que certamente recairiam sobre seu trabalho. Além desses dois autores, Gustavo Barroso se dizia leitor de Peregrinaçam de Fernão Mendes Pinto, Memórias dum soldado da Índia de Francisco Rodrigues da Silveira, Vida e feitos de El-Rei D. Manuel de Osório, Décadas de João de Barros e Diogo do Couto e História de Portugal de Oliveira Martins. Estas eram suas principais referências para realizar um maior detalhamento do chamado "espírito da época", e com isso, aprofundar em aspectos culturais e linguísticos, características da fauna e flora e, especialmente, para se tornar mais familiarizado com as histórias das grandes navegações (BARROSO, 1940, p.8-9).

Por eles também me guiei para mais certa transcrição na nossa grafia dos vocábulos indús, árabes, persas e malaios, como Pangim e não Panguim, Amboino e não Amboina ou Ambona, tôgue e não thug, xeque e não cheik, etc.

O mais que compõe o livro como enredo e desenvolvimento da acção é guisamento da minha fantasia. Se assim não fosse, teria escrito uma biografia e não um romance. (BARROSO, 1940, p.9).

Entretanto, a suposta "blindagem" de erudição que Gustavo Barroso fez uso não convenceu todos os seus companheiros da APH. Prova disso é que em 1942, sua obra foi alvo das críticas de Alfredo Pimenta (1942). Em conformidade com seu caráter sarcástico e estilo enérgico, o acadêmico português também escreveu o seu A Senhora de Pangim, que foi publicado como a Separata da Revista Brasília. Seu intuito era provocar Gustavo Barroso e desmerecer o suposto conteúdo histórico daquele trabalho. O texto tratava-se de uma breve exposição crítica em que o autor, jocosamente, relembrava do livro de Gustavo Barroso e, curiosamente, dava certa ênfase ao fato de que foi o governo português, por meio da "Agencia 
Geral das Colónias", o responsável pela publicação da suposta aventura da brasileira. O primeiro ponto a ser questionado por Alfredo Pimenta recaía exatamente sobre as referências utilizadas por Gustavo Barroso.

\begin{abstract}
A senhora de Pangim
Com êste título, o Sr. Gustavo Barroso, escritor brasileiro, e em edição da meceníssima Agencia Geral das Colónias, uma novela tecida à volta da vida de Maria Úrsula de Abreu Lencastre (...)

No prefácio, o escritor brasileiro indica como fontes as Efemérides Nacionais de Teixeira de Melo e as Efemérides Brasileiras do Barão do RioBranco; umas e outras dependem das Brasileiras Célebres de J. Noberto. (PIMENTA, 1942, p.1).
\end{abstract}

Segundo Alfredo Pimenta, antes das fontes apresentadas por Gustavo Barroso, o português Fr. João de S. Pedro, sob o pseudônimo de Damião de Fróis Perim, já havia publicado, entre 1735 e 1738, em dois volumes, a obra Theatro Heroino, Abecedario Histórico, Catalogo das Mulheres Illustres em Armas, Letras, Acçoens Heroicas e Artes Liberais. Começava ali a polêmica com o intelectual brasileiro, uma vez que o livro de Fr. João de S. Pedro sobre a aventura de D. Maria Ursula de Abreu e Lancastre, disfarçada de "soldado Balthasar do Couto Cardoso", teria sido a primeira fonte impressa do assunto. (PIMENTA, 1942, p.1-2). Ironicamente, Alfredo Pimenta relatou que se fosse somente este o "engano" do companheiro de APH, não valia a pena contestar o historiador. Mas, alguma coisa de mais grave, do ponto de vista da disciplina histórica, existia e, isso sim, era determinante para que o inquisidor português condenasse a obra à fogueira.

Deve ser esta, pois, a primeira fonte impressa do facto. Claro que só por isto, não valia a pena deslocar-me de outros temas. O que me determinou a pegar no trabalho do Sr. Gustavo Barroso foi a circunstância de êle, a pág.121, transcrever uma "carta régia" de D. João V, "despachada em Lisboa no dia 8 de Março de 1718". (PIMENTA, 1942, p.2).

Para destacar suas críticas, o polemista decidiu transcrever por completo o documento referenciado por Gustavo Barroso. Ao final da exposição, salientou que até mesmo um leigo no assunto poderia imaginar que aquela carta régia, apresentada pelo brasileiro, não passaria de um documento falso e sem nenhum valor histórico. 
Um cêgo vê que êste documento é pura fantasia. O falsário nem sequer conhecia, comesinhamente, o formulário da época. E o "contra elo", em diploma régio, do sec. XVIII, é o cumulo da invencionice, e do disparate.

Não nos diz, o Sr. Gustavo Barroso, onde encontrou o documento, a "carta régia"... despachada de Lisboa, no dia 8 de Março de 1718", e que, chegada a Goa "quási seis meses depois, foi lida, em som de pregão no terreiro do paço dos Visos Reis". Assim não me é possível inquirir as pegadas de quem forjou o diploma. (PIMENTA, 1942, p.3).

Diante disso, Alfredo Pimenta afirmou com veemência que não foi em 8 de março de 1718 que o rei concedeu a mercê aos "feitos notáveis" de D. Maria Ursula, e sim, no dia 23 de março de 1720. A comprovação dessa informação estava presente numa fonte que, na análise do intelectual, não deixaria qualquer tipo de dúvida sobre sua autenticidade. Neste mesmo documento que garantia a gratificação de D. Maria Ursula, apareciam outros personagens que também receberam mercês do rei, o que, para Alfredo Pimenta, era uma prática muito mais próxima da realidade da época.

Segundo o documento autêntico, D. Maria Ursula serviu "em praça de soldado, nas fortalezas de Moçambique, chaul e na cidade de Goa"; em 1705, esteve "na tomada de Ambona" e foi um "dos primeiros que nella entrarão"; esteve ainda "na campanha" de Bicholy citio e Batarias que se puzerão as duas fortalezas do levantado ghema saunto que as desemparou"; achou-se "nos muros de Tevim"; em 1706, foi "nomeado por cabo do baluarte Madre de Deus da fortaleza de chaul"; foi finalmente de ronda, às "prajas de Regacaim para impedir algua hostilidade". (PIMENTA, 1942, p.5).

Por outro lado, o fato de D. Maria Ursula ter recebido a "mercê da Capitania do Paço de Pangim" por seis anos, também foi alvo dos questionamentos de Alfredo Pimenta, principalmente porque indicava que o rei abria uma exceção ao caso da heroína brasileira. Segundo um alvará régio, ninguém poderia ficar mais de três anos à frente de alguma capitania ou cargo na Índia.

É por cima desta determinação, tão precisa e formal, que D. João V, em 1720, passa, para premiar os feitios da brasileira D. Maria Úrsula.

No seu Alvará de 23 de Março de 1720, o Rei esclarece que êsse diploma emana de uma Portaria do Secretário Bartolomeu de Sousa Mexia de 14 de Março de 1718, e suprimento de 9 de Março de 1720.

Tudo isto compromete a suposta "carta régia" de 8 de Março de 1718 (PIMENTA, 1942, p.7). 
Mesmo depois de realizar, de forma contundente, o desmonte da credibilidade da primeira fonte citada por Gustavo Barroso, Alfredo Pimenta não demonstrou interesse em aprofundar-se na vida da suposta heroína brasileira. Por esta razão, o intelectual não entrou na apreciação do conteúdo do Alvará de 23 de Março de 1720. Embora considerasse o documento com todas as reservas possíveis, ironizava ao dizer que naturalmente o rei foi uma vítima de informações exageradas acerca da brasileira.

Por sua vez, o episódio da tomada de Amboino, em 1705, foi cuidadosamente analisado pelo autor português. Alfredo Pimenta demonstrou que Portugal perdeu Amboino, em 1605 para os piratas holandeses, que fizeram uma incursão sobre a feitoria e acabaram por expulsar os portugueses do arquipélago. Do mesmo modo, garantia que até 1608 a coroa portuguesa ainda pensava em retomar Amboino, conforme estava registrado em documentos. Porém, a empreitada militar não passou de um projeto que jamais fora executado pela coroa. O rei acreditava que não valeria a pena o alto custo de recursos necessários para confrontar os invasores. Assim, em 1618, o próprio monarca reconhecia sua limitação por escrito e dizia com todas as letras ser impossível retomar a região dominada pelos "rebeldes hollandezes". (PIMENTA, 1942, p.7-8).

Em tom intimidador, Alfredo Pimenta desafiava Gustavo Barroso a explicar como seria possível que, em 1705, a brasileira pudesse ter sido "o primeiro soldado" a tomar Amboino, uma vez que todos os documentos existentes demonstravam que a feitoria nunca mais teria voltado a fazer parte da coroa de Portugal.

(...) o Rei declara que as ilhas e fortalezas referidas "estão tomadas por rebeldes hollandezes, e ele (requerente) não tem cabedal para conquistar de novo, nem defender".

Como é que aparece, em 1705, a tomada de Amboino, com a brasileira a fazer parte dos conquistadores, é coisa que eu não sei explicar, porque não consta que tivéssemos algum dia voltado a possuir essa Feitoria. (PIMENTA, 1942, p.8)

De maneira impiedosa, o intelectual pensava ter comprovado empiricamente a falsidade da referida "carta régia", na qual Gustavo Barroso se fundamentava. Ao mesmo tempo, considerava que todos os privilégios, supostamente dados à brasileira, haviam sido desmentidos pelo real exercício da atividade de historiador. E finalizava demonstrando todo o seu ceticismo com relação à afirmativa de que a heroína das colônias teria conseguido viver cerca de quatorze anos entre os vários homens sem levantar nenhuma suspeita do seu disfarce. 
Mas peço licença para opor o meu mais categórico cepticismo.

Devemos estar diante de uma pitoresca história da carochinha.

Não quero - e compreende-se bem o motivo - entrar em pormenores. Mas é crível que durante catorze anos, no meio da soldadesca camarada, na caserna e em campanha, uma mulher, dos dezoito aos trinta e dois anos, tenha podido iludir tôda a gente, sem que os fenómenos catameniais que lhe são próprios, manifestados, nesse período de tempo 168 vezes, pelo menos, a tivessem denunciado? (PIMENTA, 1942, p.9).

Alfredo Pimenta, categoricamente, afirmava que não acreditava na história contada por Gustavo Barroso porque seria quase impossível pensar que a voz, o corpo ou o formato do rosto não denunciariam a falsária a qualquer momento. E mais uma vez era sarcástico ao dizer que Gustavo Barroso poderia aparecer com documentos que comprovassem aquela extraordinária aventura e, assim, todo o mal entendido ficaria dado como resolvido. Porém, enquanto estas novas fontes não aparecessem, o que ficava comprovado era que o primeiro documento a registrar a recompensa do rei a Maria Ursula era de 23 de março de 1720 e não aquele que o escritor brasileiro apresentava, de 8 de março de 1718. Infelizmente, não sabemos dizer se Gustavo Barroso respondeu às críticas de Alfredo Pimenta, mas o fato é que ele, com certeza, teve acesso a esta provocação do intelectual português. Afinal, como já vimos, nos anos iniciais da década de 1940, o contato do intelectual com os ciclos intelectuais lusitanos era cada vez mais constante.

Para além de um simples episódio de disputa e demonstração egocêntrica de um homem de letras, esta polêmica historiográfica deflagrava a forma assimétrica em que se desenvolveu a relação intelectual entre Portugal e Brasil. (FREIXO, 2010). Ao contrário do sentimento de fraternidade exposto por Gustavo Barroso - e por vários outros brasileiros (FREYRE, 1953) - Alfredo Pimenta não parecia nutrir a mesma admiração pelos pares intelectuais brasileiros, posição demonstrada em várias passagens. Em uma delas, Alfredo Pimenta respondia a carta de Salazar sobre a estranheza do pensamento do ideólogo católico Tristão de Ataíde, pseudônimo de Alceu Amoroso Lima. Como era de se imaginar, Alfredo Pimenta não poupou o brasileiro de suas críticas e disparou, dizendo que do Brasil não esperava qualquer tipo de postura moral digna de admiração.

Tenho muita pena de não conhecer a entrevista de Tristão de Athayde. E nem seu se Va. Exa. Poderá através de alguns serviços, ceder-me momentaneamente o jornal em que ele veio à luz. 
Há muito tempo que ando a dizer a Va. Exa. que não tenho ilusões - nem sobre o Brasil nem sobre a Espanha, nem... sobre ninguém. A um homem de governo como Va. Exa. Só é licito ter confiança em si próprio. Quanto aos outros é de aconselhar o mais rígido cepticismo enquanto se não verificar um grau acentuado de desinteresse e independência. Diz-me Va. Exa., a proposito de Tristão de Athayde, que os filósofos não devem meter-se na política. A tese dava matéria para um ensaio largo... (PIMENTA apud CRUZ, 2008, p.194).

Diante da afirmação de Tristão de Ataíde de que os filósofos não deveriam se meter na política, Alfredo Pimenta dizia que, para começar, o brasileiro não era filósofo e sim metafísico. Isso significava dizer que o autor defendia que o filósofo poderia se envolver com a política por possuir o domínio da chamada "ciência política". Por esta razão, o pensador brasileiro estava completamente enganado e, em tom de deboche, se questionava:

Quanto a Tristão de Athayde... Quem é este homem? O que conheço dele deixou-me a impressão de que é um dos muitos moleques que há no Brasil, como este Fontoura que está aí a fingir de Embaixador e que outro dia começava um discurso desta forma: "No ano de 1500, o primeiro ano do Séc. XVI..." São desta força, os grandes homens do Brasil intelectual de hoje. (PIMENTA apud CRUZ, 2008, p.195).

Como fica evidente, enquanto Gustavo Barroso enaltecia a possibilidade de uma maior proximidade entre Brasil e Portugal, sobretudo no campo da cultura, Alfredo Pimenta olhava com certo desdém aquilo que se refere aos intelectuais brasileiros, inclusive para o próprio companheiro de APH. Gustavo Barroso escrevia obras que glorificavam a ação civilizadora de Portugal, como o Portugal Semente de Impérios, 1943, uma espécie de hino triunfante da história portuguesa. Por seu turno, Alfredo Pimenta demonstrava que o Brasil e, consequentemente, a maioria de seus pensadores estava sob o julgo da ação colonizadora dos norte-americanos e, por esta razão, eram incapazes de tomar uma atitude que despertasse admiração por parte dos eruditos portugueses. Enquanto o autor brasileiro realizou inúmeras viagens a Portugal ao longo de sua vida, algumas registradas nas atas da APH, onde participou de solenidades políticas e intelectuais, não sabemos, por outro lado, se Alfredo Pimenta chegou a conhecer o Brasil de perto. Ao que tudo indica, o autor nunca teria demonstrado qualquer tipo de interesse em fazer uma viagem à América, pois sempre considerou que o exemplo a ser seguido estava dentro da própria Europa, em especial, com os pensadores franceses contrarrevolucionários. 
Esta interação de visões de mundo e de leituras históricas que transcendiam as fronteiras nacionais e encontravam eco em ambos os lados do Atlântico, a que podemos chamar de relação transnacional (PURDY, 2011), pode ser entendida da seguinte forma: De um lado encontramos um intelectual que acreditava que Portugal seria a porta de entrada para o mundo civilizado, uma herança cosmopolita que deveria ser incorporada - postura esta que sugeria que Gustavo Barroso buscava em terras lusitanas a legitimidade e o glamour de sua própria existência. E, de outro, temos Alfredo Pimenta, um intelectual aguerrido, que mal conseguia disfarçar um sentimento que misturava pesar e indignação com a perda da antiga colônia americana, mesmo depois de se passar mais de um século desde a independência do Brasil. Este complexo sentimento de amor e ódio, nas falas do autor, emergia na forma de um espírito tutelar e patriarcal. Sendo assim, Alfredo Pimenta acreditava que o Brasil continuava sendo um "moleque" desobediente em relação à pátria-mãe e, por isso, quase sempre deveria ser repreendido.

O fato de Brasil e Portugal possuírem a mesma base linguística e, naturalmente, uma visão simbólica do mundo aparentada, dentre outras possibilidades, nos permitiu analisar com maior intimidade os pensamentos registrados nos textos de Alfredo Pimenta e Gustavo Barroso, e a partir daí, tornou-se possível sublinhar pelo menos dois traços marcantes na personalidade de ambos os intelectuais.

O primeiro e, ao mesmo tempo, mais perceptível, é o narcisismo ou o chamado "Complexo de Dora", a vaidade exacerbada que estes escritores luso-brasileiros possuíam, especialmente quando se veem diante do tribunal da história e na difícil tarefa de remontarem suas próprias trajetórias a partir da memória. Neste caso, o amor próprio, esta paixão desmedida, se aflorava sem a mínima modéstia e os autores não se incomodavam em escrever textos autobiográficos com este fim. Outros também trabalharam neste intuito, mas de forma menos direta, evitando assumir abertamente seus sentimentos. Porém, seja como for, o importante aqui é perceber que a mensagem imperativa que se camuflava nestas atitudes diferenciadas seguia pelo mesmo caminho das criações mitológicas, uma vez que ambos temiam cair no esquecimento das futuras gerações e fizeram de tudo para salvaguardar a boa memória de seus feitos heroicos.

O segundo traço que identificamos é a fórmula comum utilizada para orientar seus discursos. Os autores analisados apresentam-se ao público como a resistência hercúlea diante de forças malignas e poderosas, sejam elas conhecidas ou ocultas. Ao mesmo tempo e diante da atuação de tais ações manipuladoras da sociedade, eles não poderiam ser verdadeiramente compreendidos, restando-lhes somente a honra de cair de pé. Desta maneira, todos assumiram 
o papel de sacrifício pela nação e, em troca, pedem apenas que a história não os condene. A mensagem produzida por eles resgata um passado de glórias de onde descendem os verdadeiros heróis e igualmente se lançam no futuro como as poucas vozes da resistência. Nesta lógica, o presente é apenas um curto intervalo de tempo em que precisam aceitar as injurias dos inimigos.

Assim, ao observar de modo mais amplo, podemos dizer que ambos os intelectuais apresentados compartilhavam uma mesma visão de mundo, cujo ponto principal seria a exaltação das tradições fundadoras da nacionalidade e a permanência de valores que se contrapunham aos princípios da Revolução Francesa. Deste modo, poderíamos defini-los como defensores ou "heróis" da contrarrevolução luso-brasileira, uma vez que todos eles entendiam que o ideal de Estado em Portugal, e também no Brasil, só foi possível graças à força aglutinadora do catolicismo e do amor incondicional à terra.

Foi possível perceber também que tanto Alfredo Pimenta quanto Gustavo Barroso estavam inseridos numa conjuntura política e ideológica correlata, em que as "Primeiras Repúblicas" liberais foram colocadas no centro das críticas e das contestações. A ordem liberal, nas obras destes autores, se transformou no álibi preferido para que eles mesmos surgissem como denunciadores e libertadores, construindo uma autoimagem que identificamos pela noção de intelectual-herói. Aliás, esta foi uma característica comum, que nos permitiu analisar a produção textual dos autores pelo viés metodológico da transnacionalidade. Neste ponto, destacamos, sobretudo, as narrativas anti-materialistas e antiliberais, presentes em seus trabalhos doutrinários.

Ainda com um olhar mais genérico, confirmamos que todos eles foram intelectuais que demonstravam uma vaidade exagerada, se portavam como se fossem os detentores absolutos da verdade e do conhecimento objetivo, se viam como historiadores, sociólogos, políticos e soldados das mais altas patentes. Eram homens eruditos, no sentido exato da palavra, estudiosos e escritores compulsivos, que se aventuravam por uma vasta rede temática. Jamais se limitavam a trabalhar com um tema que não tivesse uma correlação direta com a realidade em que viviam. Os textos produzidos numa espécie de escala industrial abrangiam todos os meios de comunicação da época e, uns mais do que outros, encontravam uma grande receptividade do público.

\section{CONSIDERAÇÕES FINAIS}


O exacerbado sentimento de amor próprio manifestado por Alfredo Pimenta e por Gustavo Barroso pode ser facilmente encontrado em aulas, palestras, em textos autobiográficos e também em produções cujo assunto abordado, supostamente, não possuía nenhuma intenção de fazê-lo. Eram experts em ludibriar seus interesses e objetivos em nome do bem comum social, por isso, acreditavam sintetizar todas as angústias do mundo em suas obras. Sendo assim, esta característica transnacional de intelectual-herói, compartilhada pelos autores analisados, também pode ser identificada quando estes se dedicavam às suas criações mitológicas. Afinal, somente os heróis se tornavam mitos e eles tinham pleno conhecimento dessa máxima. Por isso, pretendiam que seus ensinamentos jamais fossem esquecidos pelas futuras gerações, aliás este sempre foi o maior de seus medos, cair no esquecimento. Diante desta lógica, fariam de tudo para controlar e salvaguardar a boa memória de suas trajetórias pessoais.

Outra fórmula comum utilizada para orientar os pensamentos desses intelectuaisheróis foi a ideia de que exerciam uma tarefa "injusta" e que muitos não reconheciam seus esforços, pois lutavam contra forças poderosas, fossem elas conhecidas ou ocultas. Mais uma vez, a extraordinária sensibilidade e a inteligência aguçada desses intelectuais se faziam presentes, principalmente, porque enquanto a maioria da sociedade era manipulada e conduzida pelo caminho da destruição, eles, os intelectuais-heróis, denunciavam e combatiam os inimigos. Esta observação nos permite salientar que tanto Alfredo Pimenta quanto Gustavo Barroso compartilhavam com os mestres da contrarrevolução a ideia de que a verdadeira história acontecia nos bastidores da sociedade, muito longe dos olhos das pessoas comuns, o que, consequentemente, fazia emergir em suas obras o famigerado mito da conspiração. Por conta do temperamento mais combativo e da personalidade mais afeita às polêmicas, os dois demonstravam mais situações em que a ideia de conspiração, pessoal ou global, era a base fundamental de seus argumentos.

Portanto, ambos os intelectuais-heróis entendiam que a maior de suas virtudes era o fato de que, mesmo diante das piores desventuras, eles sempre deveriam cair de pé, ainda que todos lutassem contra seus princípios. Eles sempre estavam dispostos a se sacrificarem, incorporando, com isso, o papel dos novos mártires, os novos messias. Nesta linha de raciocínio, a luta se transformava numa verdadeira cruzada, em que os principais inimigos seriam todos aqueles ideais difundidos pela Liberal-democracia. Esta reinterpretação da antiga tradição messiânica também pode ser identificada como a ideia do mito da salvação, uma tradição secular que tem suas origens nas histórias do povo hebreu. A boa nova que "professavam", num contexto de grandes tragédias e profundo desespero do homem, seria o

Oficina do Historiador, Porto Alegre, EDIPUCRS v. 9, n. 1, jan./jun. 2016, 
resgate de um passado de glórias e de uma época dourada, na qual eles se lançavam no futuro como os únicos e verdadeiros heróis, as últimas vozes da resistência e da inteligência, que foi restaurada graças a um processo místico e religioso que experimentaram profundamente.

\section{REFERÊNCIAS BIBLIOGRÁFICAS}

ABREU, Regina. A Fabricação do Imortal: memória, história e estratégia de consagração no Brasil. Rio de Janeiro: Rocco Lapa, 1996.

BARROSO, Gustavo. A senhora de Pangim. Lisboa: Agência Geral das Colónias, 1940.

BLOTTA, Celine Gomes da Silva. A presença brasileira nas comemorações centenárias de Portugal. Dissertação de Mestrado apresentada ao Programa de Pós-graduação em História Política da Universidade do Estado do Rio de Janeiro, 2009.

BOLETIM da Academia Portuguesa de História Acadêmico (1937-1938) Conselho. Portaria de 22 de dezembro de 1937. DIÁRIO DO GOVÊRNO, Lisboa, 1 jan. 1938.

CASSÉ, Michel \& MORIN, Edgar. Filhos do céu: entre vazio, luz e matéria. (Tradução) Edgar de Assis Carvalho, Mariza Perassi Bosco. Rio de Janeiro: Bertrand Brasil, 2008.

COSTA, Luiz Mário F. Os “intelectuais-heróis" e as mitologias políticas contemporâneas: a história transnacional da produção intelectual de Alfredo Pimenta, Gustavo Barroso, Plínio Salgado e Rolão Preto. 2015. 198f. (Tese em História). Universidade Federal de Juiz de Fora, Juiz de Fora, 2015.

CRUZ, Manuel Braga da. Prefácio. Salazar e Alfredo Pimenta. Correspondência (1931 1950). Lisboa: Verbo, 2008.

FERREIRA, Tito Lívio. Portugal no Brasil e no Mundo. vol.2. São Paulo: Academia Paulista da História, 1994.

FREIXO, Adriano de. As relações luso-brasileiras e a CPLP. Algumas reflexões em torno da ideia da lusofonia. In: As Relações Portugal-Brasil no século XX. (Coord.) SOUSA, Fernando de; SANTOS, Paula; AMORIM, Paulo. Porto: Fronteira do Caos Editores Lda. 2010.

FREYRE, Gilberto. Um Brasileiro em Terras Portuguesas: Introdução a uma possível luso-tropicologia, acompanhada de conferencias e discursos proferidos em Portugal e em terras lusitanas e ex-lusitanas da Ásia, da África e do Atlântico. Rio de Janeiro: José Olympio. 1953.

JACOBELIS, Paola Gentile. Contradição, engajamento e liberdade: reflexões de Sartre sobre o intelectual no século XX. 2012. Dissertação (Mestrado em Filosofia) Universidade de São Paulo, SP, 2012. Disponível em:

<http://www.teses.usp.br/teses/disponiveis/8/8133/tde-30082012-114500/pt-br.php>. Acesso em 13 fev. 2015.

MORIN, Edgar. Introdução ao pensamento complexo. (Tradução) Eliane Lisboa. 5ed. Porto Alegre: Sulina, 2015. 
NUNES, Catarina Silva. Compromissos incontestados: A auto-representação dos intelectuais católicos portugueses. Lisboa: Paulinas, 2005.

OLIVEIRA, Lucia Lippi. Elite intelectual e debate político nos anos 30: uma bibliografia comentada da revolução de 1930. Rio de Janeiro: Fundação Getúlio Vargas, 1980.

PIMENTA, Alfredo. A Senhora de Pangim. Coimbra: Coimbra Editora, 1942.

PURDY, Sean. História Comparada e o Desafio da transnacionalidade. Revista de História Comparada. Rio de Janeiro, 6-1, marc/abr. 2011. Disponível em:

<http://www.hcomparada.historia.ufrj.br/revistahc/artigos/volume006_Num001_artigo003.p df $>$. Acesso em 12 fev. 2015.

SANTOS, Paula Marques dos \& AMORIM, Paulo. As relações Portugal-Brasil na Primeira metade do século XX (1910-1945). In: As Relações Portugal-Brasil no século XX.

(Coord.) SOUSA, Fernando de; SANTOS, Paula; AMORIM, Paulo. Porto: Fronteira do Caos Editores Lda. 2010.

WINOCK, Michel. O século dos intelectuais. Tradução de Eloá Jacobina. Rio de Janeiro: Bertrand Brasil, 2000.

ZINN, Howard. Você não pode ser neutro num trem em movimento: uma história pessoal dos nossos tempos. Tradução de Nils Goran Skare. Curitiba: L-Dopä Publicações, 2005.

ARTIGO ENVIADO EM: 04/01/2016

ARTIGO ACEITO PARA PUBLICAÇÃO EM: 06/06/2016 